PAPER • OPEN ACCESS

Guided bone tissue regeneration using a hollow calcium phosphate based implant in a critical size rabbit radius defect

To cite this article: Mellgren Torbjörn et al 2021 Biomed. Mater. 16035018

View the article online for updates and enhancements.

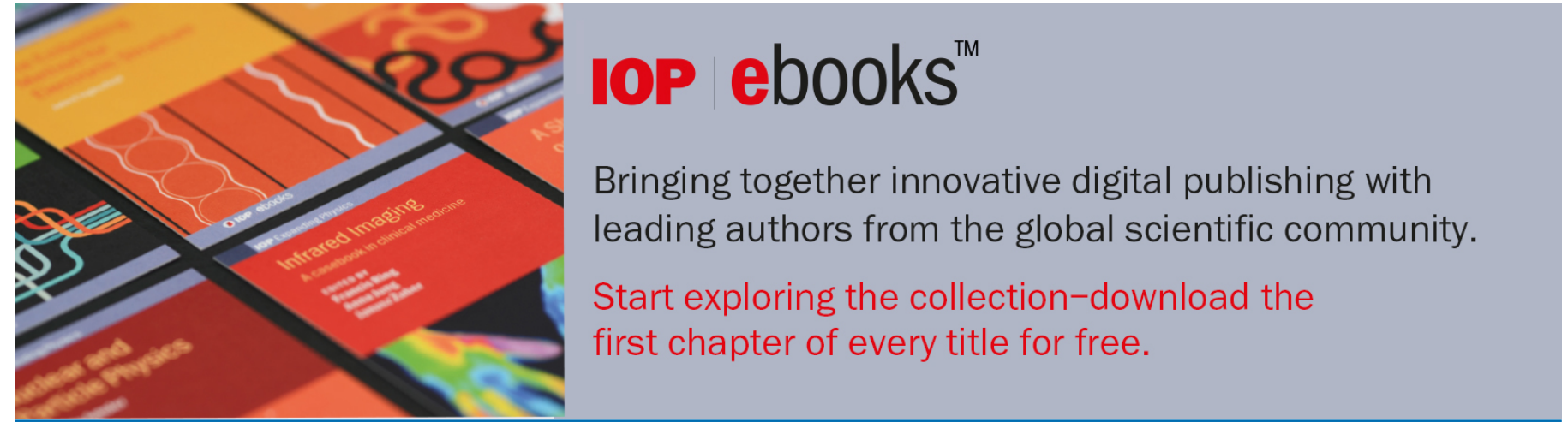

This content was downloaded from IP address 130.238 .188 .182 on $21 / 04 / 2021$ at $15: 19$ 


\title{
Biomedical Materials
}

\begin{tabular}{|c|c|}
\hline OPEN ACCESS & $\begin{array}{l}\text { PAPER } \\
\text { Guided bone tissue regeneration using a hollow calcium } \\
\text { phosphate based implant in a critical size rabbit radius defect }\end{array}$ \\
\hline $\begin{array}{l}\text { RECEIVED } \\
31 \text { January } 2020\end{array}$ & Mellgren Torbjörn ${ }^{1,6}$, Trbakovic Amela $^{2,6}$, Thor Andreas $^{2}$, Ekman Stina $^{3}$, Ley Cecilia ${ }^{3}$, \\
\hline $\begin{array}{l}\text { REVISED } \\
27 \text { October } 2020\end{array}$ & $\begin{array}{l}\text { Öhman-Mägi Caroline }{ }^{1} \text { (D), Hammarström Johansson Petra }{ }^{4} \text {, Jensen-Waern Marianne }{ }^{5} \\
\text { and Hedenqvist Patricia }\end{array}$ \\
\hline 21 January 2021 & $\begin{array}{l}1 \text { Department of Materials Science and Engineering, Division of Applied Materials Science, Materials in Medicine Group, } \\
\text { Uppsala University, PO Box 534, 75121 Uppsala, Sweden }\end{array}$ \\
\hline 3 March 2021 & $\begin{array}{l}\text { Department of Surgical Sciences, Plastic \& Oral and Maxillofacial Surgery, Uppsala University, } 75185 \text { Uppsala, Sweden } \\
3 \text { Department of Biomedical Sciences and Veterinary Public Health, Division of Pathology, Swedish University of Agricultural Sciences, } \\
\text { PO Box 7028, } 75007 \text { Uppsala, Sweden }\end{array}$ \\
\hline $\begin{array}{l}\text { Original content from } \\
\text { this work may be used } \\
\text { under the terms of the } \\
\text { Creative Commons } \\
\text { Attribution } 4.0 \text { licence. }\end{array}$ & $\begin{array}{l}\text { The Sahlgrenska Academy, Institute of Odontology, Department of Prosthodontics/Dental Materials Science, University of Gothenburg, } \\
5 \text { Do Box 450, } 40530 \text { Gothenburg, Sweden } \\
6 \text { Department of Clinical Sciences, Swedish University of Agricultural Sciences, PO Box 7054, } 75007 \text { Uppsala, Sweden } \\
\text { Equal contribution. }\end{array}$ \\
\hline $\begin{array}{l}\text { Any further distribution } \\
\text { of this work must } \\
\text { maintain attribution to } \\
\text { the author(s) and the title } \\
\text { of the work, journal } \\
\text { citation and DOI. }\end{array}$ & Keywords: $3 \mathrm{D}$ printing, bone augmentation, bone substitute, long bone, in vivo \\
\hline
\end{tabular}

\begin{abstract}
Long bone fractures are common and sometimes difficult to treat. Autologous bone (AB), bovine bone and calcium phosphates are used to stimulate bone growth with varying results. In the present study, a calcium phosphate cement (CPC) that previously showed promising grafting capabilities was evaluated for the first time in a long bone defect. A radius defect of $20 \mathrm{~mm}$ was created in 20 rabbits. The defect was filled by either a hollow CPC implant that had been manufactured as a replica of a rabbit radius through indirect $3 \mathrm{D}$ printing, or by particulate $\mathrm{AB}$ as control. Defect filling and bone formation was evaluated after 12 weeks by combining micro computed tomography $(\mu \mathrm{CT})$ and scoring of $3 \mathrm{D}$ images, together with histomorphometry and histology. The $\mu \mathrm{CT}$ and histomorphometric evaluations showed a similar amount of filling of the defect (combining graft and bone) between the $\mathrm{CPC}$ and $\mathrm{AB}$ group, but the scoring of $3 \mathrm{D}$ images showed that the filling in the CPC group was significantly larger. Histologically the AB graft could not be distinguished from the new bone. The $\mathrm{AB}$ treated defects were found to be composed of more bone than the CPC group, including reorganised cancellous and cortical bone. Both the CPC and $\mathrm{AB}$ material was associated with new bone formation, also in the middle of the defect, which could result in closing of the otherwise critically sized gap. This study shows the potential for an indirectly $3 \mathrm{D}$ printed implant in guided bone regeneration in critically sized long bone defects.
\end{abstract}

\section{Introduction}

There are conditions in which the body's own bonegenerating abilities are insufficient to heal a fracture or to fill a bone void. For example, bone defects can be so large that they are deemed unlikely to heal without bone augmentation treatment (critical defects). Long bone fractures are rather common, e.g. the incidence of tibia fractures in Sweden is 51.7 per 100000 and year [1]. Fracture treatment in long bones is a challenge; approximately $10 \%$ of patients need to be readmitted due to non-union, delayed union or malunion of the fracture [2]. The complication rate of long bone fractures together with the high incidence of complications puts urgency on developing better treatments.

The gold standard treatment of bone voids is to use autologous bone (AB) [3] as a graft material, but donor site complications such as pain and infections [4], resorption of the graft $[5,6]$ and the limited supply of bone to harvest, bring a need for alternatives. Synthetic bone substitute materials are a possible solution to these problems. Calcium phosphates are widely used as a substitute to $A B$ due to their biocompatibility, osteoconductivity and chemical similarity to the mineral part of osseous 
tissue [7]. However, all calcium phosphate materials do not behave in the same manner, and therefore large efforts have been carried out to optimize properties such as phase composition, substitute ions, porosity, drug delivery and implant design [8-10]. Recently, a particular calcium phosphate formulation containing monetite, $\beta$-tricalcium phosphate $(\beta$-TCP) and $\beta$-calcium pyrophosphate $(\beta$-CCP) has demonstrated promising bone regenerating properties in vivo [11-15]. The formulation was developed for use in a solid mosaic-scaffold for patients with severe skull defects, in which it was shown that vascularized bone covered the material after 50 months $[11,12]$. In a recent study, using a sinus lift model in rabbits, the same calcium phosphate cement (CPC) formulation was evaluated in a granular form with promising results of bone formation [13]. Twelve weeks after implantation, the amount of bone formation was equivalent to controls with bovine bone chips, which are currently commonly used for restoring alveolar bone [13]. It would therefore be of interest to investigate if this CPC formulation could be used for bridging of critical size defects in long bones. The microstructure, mechanical properties and porosity of the material have also been investigated in previous studies $[12,16]$.

The progress in rapid prototyping has expanded the potential for patient specific implants with the possibility of designing and manufacturing biomaterials of intricate geometry in a fast and affordable way [17-20]. Cements can be used in robocasting, a technique where the cement is ejected through a nozzle and $3 \mathrm{D}$ printed. However, for the cement to be able to flow through the nozzle, the formulations have to be adjusted, which can result in weak mechanical properties [21]. Reinforcing additives can be used to mediate this limitation [22]. Another alternative is to use indirect $3 \mathrm{D}$ printing, where a mould is $3 \mathrm{D}$ printed and the cement casted therein. The latter technique allow the use of cement formulations that have been developed for traditional casting such as the one used in this study.

A standard model for testing of biomaterials in long bones is a segmental radius bone defect in rabbits [23]. Some of the advantages of using rabbits are their intermediate size, the low cost in comparison with the use of larger animals, and a greater similarity to human bone anatomy in comparison with rodents [24]. In previous studies, defects of 14$20 \mathrm{~mm}$ have been demonstrated to be critical and the model is useful because the ulnar bone upholds stability, thus no further fixation of the radius is needed $[25,26]$.

The aim of the present study was to combine the promising cement formulation with the indirect $3 \mathrm{D}$ printing method to produce and evaluate a synthetic copy of the missing bone in a critical radius defect in a rabbit. Replacement with $\mathrm{AB}$ chips served as a reference. Further, the aim was to observe the location of bone formation in relation to the radius defect, i.e. how well the tissue regeneration was guided by the different graft materials.

\section{Materials and methods}

\subsection{Animals}

Twenty female New Zealand White rabbits (Lidköpings kaninfarm, Lidköping, Sweden), 910 months of age and with a mean \pm SD body weight of $3.9 \pm 0.5 \mathrm{~kg}$ were used. Uppsala animal ethics committee had reviewed and approved the study (C 70/13). National guidelines for the care and use of laboratory animals were followed [27]. The colony of origin was screened according to European guidelines [28] and found free from common rabbit pathogens. The rabbits were acclimatized for 2 weeks during which they were trained to handling. The rabbits were either pair housed in floor pens of $3 \mathrm{~m}^{2}$, with aspen bedding and two plastic houses for hiding $(n=10)$, or singly housed in cages of $0.43 \mathrm{~m}^{2}$ (EC2 rack, Scanbur, Karlslunde, Denmark) with a perforated plastic floor and a shelf/hiding area $(n=10)$. Water, autoclaved straw and hay were available $a d$ lib. A restricted portion of pelleted feed (Lactamin K1, Lantmännen, Stockholm, Sweden) was offered every day. The light cycle was $12: 12$, the temperature $18.5^{\circ} \mathrm{C}-20.7^{\circ} \mathrm{C}$ and the relative humidity $42 \%-66 \%$.

\subsection{Study design}

A $2 \times 2$ factorial design was used to study two materials and two housing conditions simultaneously to keep the number of animals to a minimum. The treatments were (a) CPC implant and (b) AB graft, and the housing conditions (a) single housing in $0.43 \mathrm{~m}^{2}$ cages and (b) pair-housing in $3 \mathrm{~m}^{2}$ floor pens. The rabbits were randomly distributed to one of four combinations:

(a) CPC implant + cage housing $(n=5)$

(b) CPC implant + floor housing $(n=5)$

(c) $\mathrm{AB}$ graft + cage housing $(n=5)$

(d) AB graft + floor housing $(n=5)$

The effect of housing was the same for both materials and is presented in detail elsewhere [29].

\subsection{Calcium phosphate implant manufacturing}

The implant design was based on a pilot cadaver study, using the same surgical procedure as described in section 2.5. The removed part of the radius was scanned using micro computed tomography ( $\mu \mathrm{CT}$, SkyScan 1172, Bruker MicroCT, Kontich, Belgium). The bone was kept in formalin solution inside a cylindrical PMMA sample holder during the scan. A voltage of $80 \mathrm{kV}$, a current of $124 \mu \mathrm{A}$ and a $0.5 \mathrm{~mm}$ aluminium filter was used to acquire images with an isotropic pixel size of $9.0 \mu \mathrm{m}^{2}$. The images were reconstructed using software package NRecon 


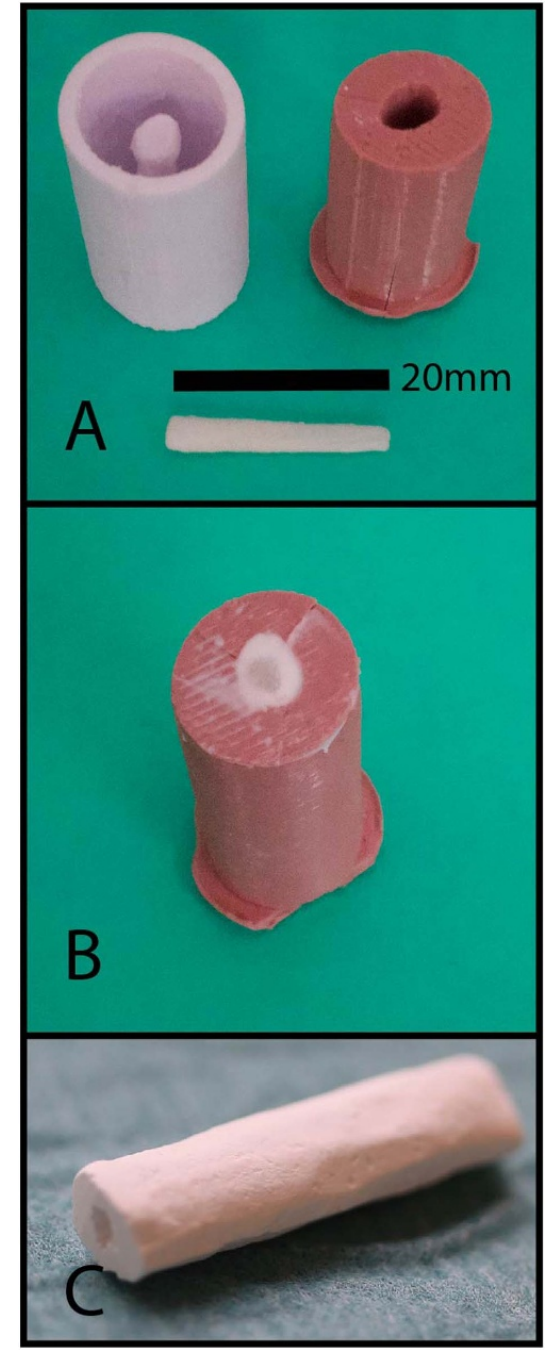

Figure 1. Photos showing the manufacturing steps of the calcium phosphate cement implants: (A) 3D printed PLA template (white) with corresponding silicon mould (red) and the water-soluble medullary cavity insert. (B) The silicon mould filled with cement and the insert in the middle. (C) The cured and autoclaved implant.

(Bruker MicroCT, Kontich, Belgium), a 3D-model was created with CTAn (Bruker microCT, Kontich, Belgium), which was exported to a CAD software (Autocad, Autodesk Inc., San Rafael, CA, USA). CAD software was used to design a replica of the excised radius bone that could be $3 \mathrm{D}$-printed. A $3 \mathrm{D}$-model based on the medullary cavity was also designed, the diameter of the model was however reduced by $20 \%$ to ensure mechanical stability.

The radius replica was 3D-printed (Makerbot 5 th generation, Makerbot Industries LLC, Brooklyn, New York, USA) using a PLA filament (True White PLA, Makerbot). A casting mould using the radius replica was then produced using silicon rubber (Elastosil M4601 A/B, Wacker Chemie AG, Munich, Germany). The model of the reduced medullary cavity was 3D-printed (Makerbot Replicator 2) using a water-soluble polyvinyl alcohol filament (water soluble, Makerbot) (figure 1(A)).
The CPC was prepared by mixing $\beta$-TCP (SigmaAldrich) that contained $\beta$-CPP and monocalcium phosphate monohydreate (Scharlau) in the mass ratio 55.2:44.8, the powder mixture was then blended with glycerol (powder to liquid ratio of $3.9 \mathrm{~g} \mathrm{ml}^{-1}$ ). After preparation, the cement was immediately injected into the silicon radius mould and the water-soluble replica of the medullary cavity was pushed into the centre of the cement filled mould (figure 1(B)). The implants were left to cure submerged in sterile and distilled water at $37^{\circ} \mathrm{C}$ for $4 \mathrm{~d}$, the water was refreshed after $2 \mathrm{~d}$. The replica of the medullary cavity was fully resorbed in the water leaving a canal. The implants were carefully removed from the moulds and checked for any visible defects and left to dry in room temperature for $24 \mathrm{~h}$, before they were packaged and sterilized in an autoclave at $121{ }^{\circ} \mathrm{C}$ for $20 \mathrm{~min}$ (figure $1(\mathrm{C})$ ).

\subsection{Crystal phase characterization}

The crystal phase composition of the set CPC was characterized using $\mathrm{X}$-ray powder diffraction analysis (XRD, D8 Advanced, Bruker AXS GmbH, Karlsruhe, Germany). Implants that were visibly defective, due to e.g. cracks, were ground to a fine powder using a mortar and pestle and mixed together to obtain the amount needed for analysis. From the cement powder six samples were prepared and scanned using a thetatheta setup. $\mathrm{Cu}-\mathrm{K}$ alpha radiation with a nickel filter, a beam knife and rotation of $80 \mathrm{rpm}$ were used. Diffraction data was collected from $2 \theta 5-60^{\circ}$ with steps of $0.019^{\circ}$ and scan time of $0.25 \mathrm{~s} \mathrm{step}^{-1}$. The different phases present in the cement were quantified with Rietveld refinement using software BGMN (www.bgmn.de) [30, 31] with Profex user interface (Profex 3.11.1, http://doebelin.org) [32]. The references crystal phases were PDF\#04-013-3344 [33] for brushite, PDF\#04-008-8714 [34] for $\beta$-TCP, PDF\#04009-3876 [34] for $\beta$-CPP and PDF\#04-009-3755 [35] for monetite. Following the ASTM E177-14 standard [36] the mean of six measurements was used and the repeatability equals 2.77 times the standard deviation.

\subsection{Surgery}

For anaesthesia, medetomidine $\left(0.25 \mathrm{mg} \mathrm{kg}^{-1}\right.$, Domitor $1 \mathrm{mg} \mathrm{ml}^{-1}$, Orion Pharma AB Animal Health, Danderyd, Sweden) and ketamine (15 $\mathrm{mg} \mathrm{kg}^{-1}$, Ketalar $50 \mathrm{mg} \mathrm{ml}^{-1}$, Intervet $\mathrm{AB}$, Stockholm, Sweden) were mixed and administered subcutaneously (SC). Local anaesthetic cream (EMLA, AstraZeneca, Sweden) was applied on the skin over the ear veins and arteries. For pre-emptive analgesia, $5 \mathrm{mg} \mathrm{kg}^{-1}$ of the NSAID carprofen (Rimadyl, Orion Pharma, $50 \mathrm{mg} \mathrm{ml}^{-1}$, Sollentuna, Sweden) was administered $\mathrm{SC}$, and for infection control $10 \mathrm{mg} \mathrm{kg}^{-1}$ ceftiofur (Excenel $50 \mathrm{mg} \mathrm{ml}^{-1}$, Orion Pharma, Sollentuna, Sweden) intramuscularly. A local anaesthetic block was performed by injection of $3 \mathrm{mg} \mathrm{kg}^{-1}$ of ropivacaine (Ropivacain $10 \mathrm{mg} \mathrm{ml}^{-1}$, Fresenius Kabi AB, 
Uppsala, Sweden) in the axillary area. For the measurement of blood pressure and infusion of fluids, catheters were placed in the ear artery (Venflon, 18G, Becton Dickinson AB, Stockholm, Sweden) and vein (Venflon, 20G) and filled with a heparin lock-solution (100 IE ml ${ }^{-1}$, Heparin Leo, Leo Pharma AB, Malmö, Sweden). After clipping of fur, the skin in the surgical area was aseptically prepared.

A larynx mask (V-gel, large, Docsinnovent, London, UK) and a paediatric breathing system (Intersurgical Ltd, Wokingham, UK) were used to provide oxygen $\left(1.5 \mathrm{l} \mathrm{min}^{-1}\right)$ and isoflurane as needed, from the anaesthesia machine (Anmedic Q-Circle System; Anmedic AB, Stockholm, Sweden). Arterial blood pressure, heart rate, rectal temperature, end tidal $\mathrm{CO}_{2}$ and respiratory rate were continuously monitored (CS/3, Datex-Engstrom, Helsinki, Finland). A heating pad was used as needed for stabilising the body temperature. A $50 \mathrm{~mm}$ longitudinal skin incision was made along the radius, followed by dissection of the muscles and exposure of the radial bone. A $20 \mathrm{~mm}$ long piece of the radius together with the periosteum was removed mid-shaft with help of a prefabricated guide-template, with Pietzo surgery ( $\mathrm{Mec}-$ tron, Carasco, Italy), under continuous saline cooling. The defect was either replaced with the CPC implant or particulated $\mathrm{AB}$ (figure 2). In the latter case, the removed radius was ground into $1-3 \mathrm{~mm}$ bone chips with a manual bone mill (The R. Quétin Bone-Mill, KLS Martin, Jacksonville, FL, USA). The particulated bone was held in place by a collagenous membrane (figure 2(B)). The membrane $(25 \times 25 \mathrm{~mm}$, Geistlich Bio-Gide, Geistlich Pharma AG, Wolhusen, Switzerland) formed a cylindrical scaffold, which held the bone chips in place like an envelope. No additional fixation was used. Finally, the soft tissue was closed in separate layers using resorbable monocryl sutures 5-0 (Ethicon, Johnsons \& Johnson AB). The surgery lasted for 60-90 $\mathrm{min}$.

\subsection{Postoperative care and gross pathology}

After completion of surgery, the rabbits were placed in a heated chamber at $21{ }^{\circ} \mathrm{C}-26{ }^{\circ} \mathrm{C}$ until fully awake. For analgesia, buprenorphine (Temgesic, $0.3 \mathrm{mg} \mathrm{ml}^{-1}$, Indivior UK Ltd, Slough, Berkshire, UK) was administered SC (0.05 $\left.\mathrm{mg} \mathrm{kg}^{-1}, n=10\right)$ or by buccal administration $\left(0.15 \mathrm{mg} \mathrm{kg}^{-1}, n=10\right)$. For measurements of buprenorphine plasma levels, blood was repeatedly collected [37]. Buprenorphine administration was repeated by the initial route after $8 \mathrm{~h}$, and thereafter SC in all rabbits every $8 \mathrm{~h}$ for $3 \mathrm{~d}$, in a tapered dose $\left(0.05-0.03 \mathrm{mg} \mathrm{kg}^{-1}\right)$. Additionally, for pain relief, carprofen was administered SC 24 and $48 \mathrm{~h}$ post-surgery. The rabbits were examined, and body weight was recorded daily during the first two postoperative weeks, thereafter weekly.

After 12 weeks, the rabbits were euthanized with pentobarbital (Allfatal vet. Omnidea AB, Stockholm, Sweden) injected in the ear vein. All

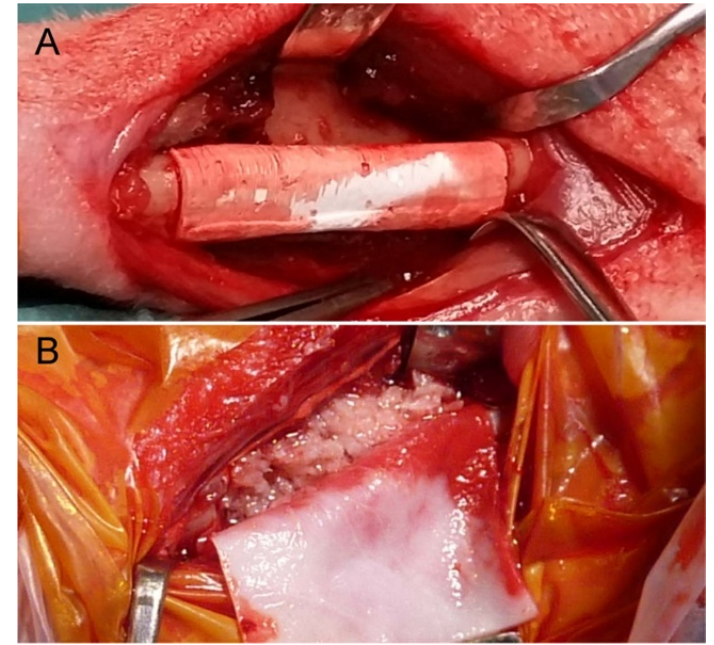

Figure 2. Images showing the radius defects during surgical insertions of (A) the CPC implant and (B) the particulated $\mathrm{AB}$ before the collagen membrane is folded over the graft.

animals were examined by gross pathology. The front limbs were removed using a band saw (KT-400, Klaukkala, Finland). The bones were immersed in $10 \%$ neutral-buffered formalin fixative. The samples were trimmed down rendering a final sample size of about $35 \times 10 \mathrm{~mm}$.

\section{7. $\mu \mathrm{CT}$ analyses}

\subsubsection{Qualitative $\mu C T$ evaluation}

Virtual 3D-models of the radii (CTVox, Bruker Micro CT) were used to subjectively evaluate the defect union (union/non-union), degree of bridging (score 1-4) and degree of filling of the defect (combining bone and graft) (score 1-4), as in the study by Bodde et al [38] (figure 3). Three of the authors (ATr, TM, $\mathrm{PH}$ ) performed the evaluation independently.

\subsubsection{Quantitative $\mu C T$ evaluation}

Both front limbs from each rabbit were scanned post-mortem with the same settings described in section 2.3, with the addition that bone mineral density (BMD) reference samples (medium 8-16 mm BMD phantom set, Bruker MicroCT, Kontich, Belgium) were scanned once per day to quantify the bone density and facilitate inter-study comparisons. Cross-sections of radii and phantoms were reconstructed using the NRecon software package (Bruker MicroCT, Kontich, Belgium). All analyses were performed using the software package CTAn (Bruker MicroCT, Belgium).

The amount and density of new bone and graft material was evaluated both inside the volume previously occupied by the radius (restricted volume) and in a volume without transversal restrictions (unrestricted volume) (figure 4). For the unrestricted volume the ulna from the unoperated front limb was used to estimate and subtract the volume of the ulna on the defect side. The restricted volume was created 


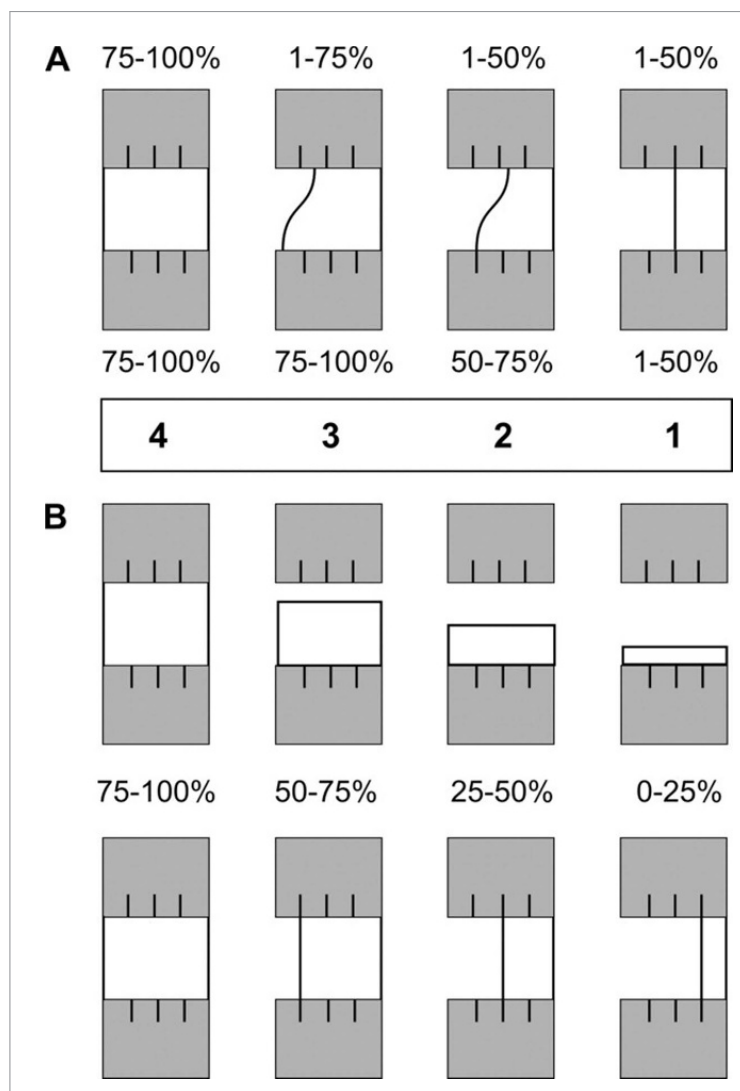

Figure 3. Illustration of the scoring system used for the qualitative radiographic evaluation of virtual 3D-models of the defects. (A) The degree of bridging was defined as the fraction of contact surface between the material and radius bone. (B) The filling of the defect was taken as the fraction of the defect volume that was occupied by material or bone. (Reproduced from Bodde et al with kind permission.)

by interpolation between the ends of the radius bone from both sides of the defect (CT An, Bruker Micro $\mathrm{CT}$ ). The same methods were also used to evaluate the central $10 \mathrm{~mm}$ of the defect (figure 4 ).

\subsection{Histology}

\subsubsection{Sample processing}

Preparation of un-decalcified sections followed the guidelines proposed by Donath et al [39, 40] and Johansson et al [41, 42] using cutting and grinding equipment (Exakt Appartebau, Nordstedt, Germany). To enhance dehydration and infiltration of the various liquids, the samples were stirred and treated under vacuum. Increasing concentrations of ethanol were followed by pre-infiltration in diluted resin concentrations, and finally pure resin (Technovit 7200/VLC light curling resin Kultzer, Germany). Two transversal sections were cut from the middle of the defects with a diamond coated sawing band. Following this, the samples were glued together to their original shapes (Loctite, super glue Henkel Norden AB, Stockholm) before being cut to give longitudinal sections. All sections were ground to render a final section thickness of $20-30 \mu \mathrm{m}$. A solution containing $1 \%$ toluidine blue dissolved in $1 \%$ borax and mixed with $1 \%$ pyronin $\mathrm{G}$ was used for staining.

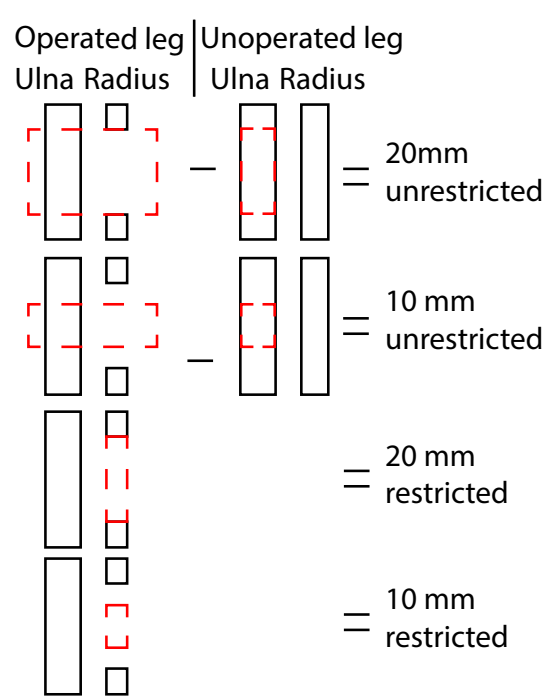

Figure 4. Illustration of the volumes in which the density and volume of the new bone combined with CPC and autologous bone were quantified. Outlined in red are the volumes measured on the operated leg (left side), from which the volumes on the intact leg were subtracted (right side). The unrestricted volumes took new bone and material within and around the defect area into account, whereas the restricted volume was based on the defect area alone.

\subsubsection{Histomorphometry}

All longitudinal sections were photographed with objective $1 \times(10 \times$ magnification $)$ with a Nikon E600 light microscope and a Nikon DXM 1200 camera (Nikon Instruments, Melville, NY, USA) connected to a PC. All slides were photographed under the same conditions in regard to exposure time, light intensity, and camera gain. The analysis was performed using NIS-elements imaging software (NIS-elements Basic Research, Nikon, Tokyo, Japan). White balance adjustments, calibrations, and transformations of the photographs into binary images were performed for each captured image. The measurements were performed on an area restricted radially by the defect ends, and laterally by the original ulnar bone and the outer boarder of the material and/or bone (figure 5). The area of tissue filled by graft material and bone was compared between $\mathrm{CPC}$ and $\mathrm{AB}$ treated defects.

\subsubsection{Qualitative scoring}

Sections were examined for qualitative morphologic healing by light microscopy (Nikon eclipse E600, Nikon Instruments, Melville, NY, USA). Blinding was not possible since CPC was visible in all sections. After individual scoring, the three examiners (SE, CL, ATr) agreed on a consensus scoring.

The longitudinal sections, one per animal, were examined and scored for: (a) new bone formation adjacent to the defect ends; (b) cortical integrity on the opposite side of the ulnar bone; (c) presence of cancellous bone; (d) presence of inflammation; (e) defect filling composition; (f) bony fusion with ulna in the defect area; $(\mathrm{g}$ ) bony fusion between ulna 

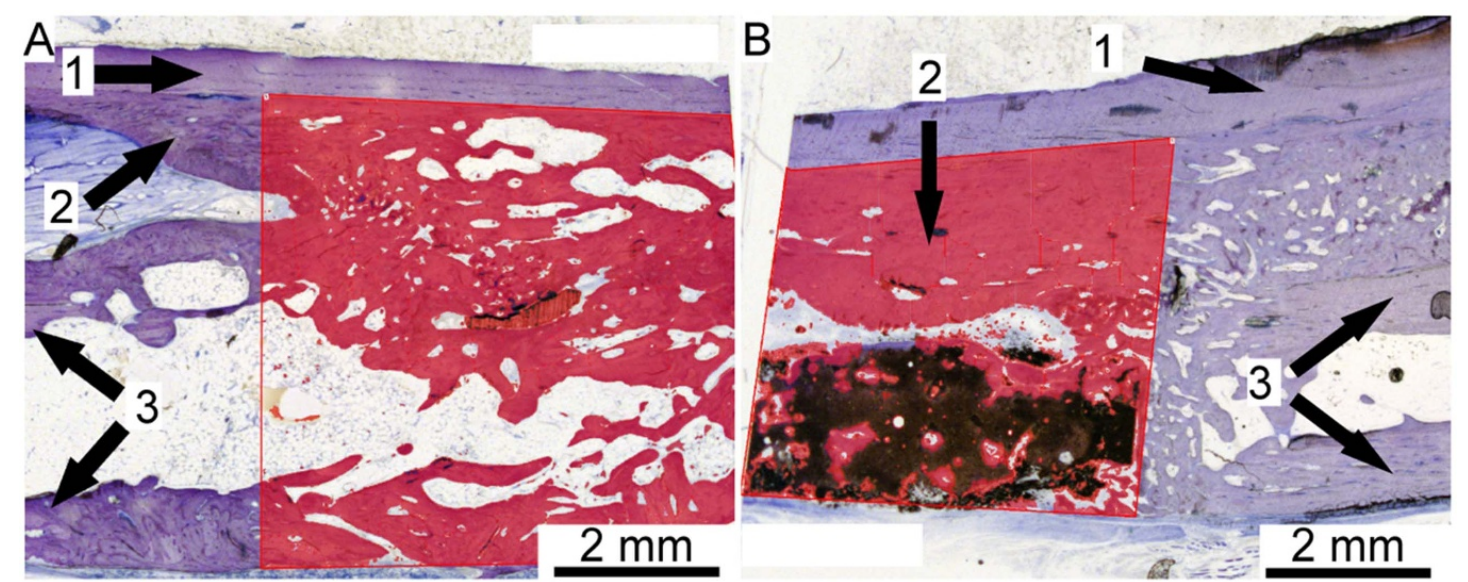

Figure 5. The figure presents two different histology sections of the defect area: (A) an AB section and (B) a CPC section with dark brown coloured material. The bone found in the defect is coloured red. The arrows point at (1) the ulnar bone; (2) proliferation of the ulnar bone and (3) the radius bone. The marked quadrants outline the areas on which histomorphometry measurements were based, which include the ulnar periosteal bone formation (2).

Table 1. Histology scoring scheme showing the criteria scored (a-g) and the characteristics of the scores (1-4).

\begin{tabular}{lllll}
\hline & \multicolumn{5}{c}{ Score } \\
\cline { 2 - 6 } Categories & 1 & 2 & 3 & 4 \\
\hline
\end{tabular}

(a) New bone form- No integration One edge integrated Both edges integrated
ation associated with defect ends

\begin{tabular}{|c|c|c|c|c|}
\hline $\begin{array}{l}\text { (b) Cortical integrity } \\
\text { (peripheral surface) }\end{array}$ & Periosteal fibrosis & $\begin{array}{l}\text { Initiation of forma- } \\
\text { tion of lamellar bone }\end{array}$ & $\begin{array}{l}\text { Reorganization in } \\
\text { majority }\end{array}$ & $\begin{array}{l}\text { Complete integrity of } \\
\text { cortical bone }\end{array}$ \\
\hline $\begin{array}{l}\text { (c) Presence of Can- } \\
\text { cellous bone }\end{array}$ & $\begin{array}{l}\text { Woven bone associ- } \\
\text { ated with graft }\end{array}$ & $\begin{array}{l}\text { Lamellar and woven } \\
\text { bone associated with } \\
\text { graft }\end{array}$ & $\begin{array}{l}\text { Lamellar and woven } \\
\text { bone-no graft seen }\end{array}$ & $\begin{array}{l}\text { Complete reorgan- } \\
\text { ization of cancellous } \\
\text { bone }\end{array}$ \\
\hline (d) Inflammation & $\begin{array}{l}\text { Multiple areas of }>20 \\
\text { monocytes in a high } \\
\text { power field }(\times 400)\end{array}$ & No inflammation & - & - \\
\hline $\begin{array}{l}\text { (e) Defect filling com- } \\
\text { position }\end{array}$ & $\begin{array}{l}\text { Filled with graft, bone } \\
\text { and fibrous tissue }\end{array}$ & $\begin{array}{l}\text { Areas of fibrocartilage } \\
\text { in the bone }\end{array}$ & $\begin{array}{l}\text { Only bone fill the } \\
\text { defect }\end{array}$ & - \\
\hline $\begin{array}{l}\text { (f) Bony fusion with } \\
\text { ulna at the defect }\end{array}$ & No fusion & Fusion & - & - \\
\hline $\begin{array}{l}\text { (g) Bony fusion } \\
\text { between ulna and } \\
\text { radius adjacent to } \\
\text { defect }\end{array}$ & No fusion & Fusion & - & - \\
\hline
\end{tabular}

and radius adjacent to the defect. For the transversal sections, which were taken from the middle of the defects, an average of two sections per animal were evaluated and only categories b, c, d, f were included and scored (table 1).

\subsection{Statistical evaluation}

InVivoStat version 3.7.0.0. (Copyright 2008-2016. Simon Bate \& Robin Clark), SPSS version 24 (IBM, New York, USA) and SAS/STAT (SAS Institute AB, Solna Sweden) were used for statistical evaluation. The data were analysed using a two-way ANOVA approach, with material and housing as treatment factors. If there was no interaction between material and housing, the results from each material was averaged across housing condition and a single comparison made between materials [43] with LSD test (parametric data) or Mann-Whitney U test (nonparametric data) [44]. The data for the restricted and unrestricted volumes of interests (VOIs) for defect filling were analysed using an extended paired t-test, with restricted/unrestricted VOI as factor and material and housing as blocking factors. Statistical significance was set at the $p<0.05$ level. Values are presented as mean (SEM) or median (range). For scoring, the correlations between observer scores were computed as polychoric correlations using the FREQ procedure.

\section{Results}

There was no interaction between material and housing condition. Floor housed rabbits showed a larger bone defect filling volume, a lower bone density and a higher score of bony fusion between radius and ulna 


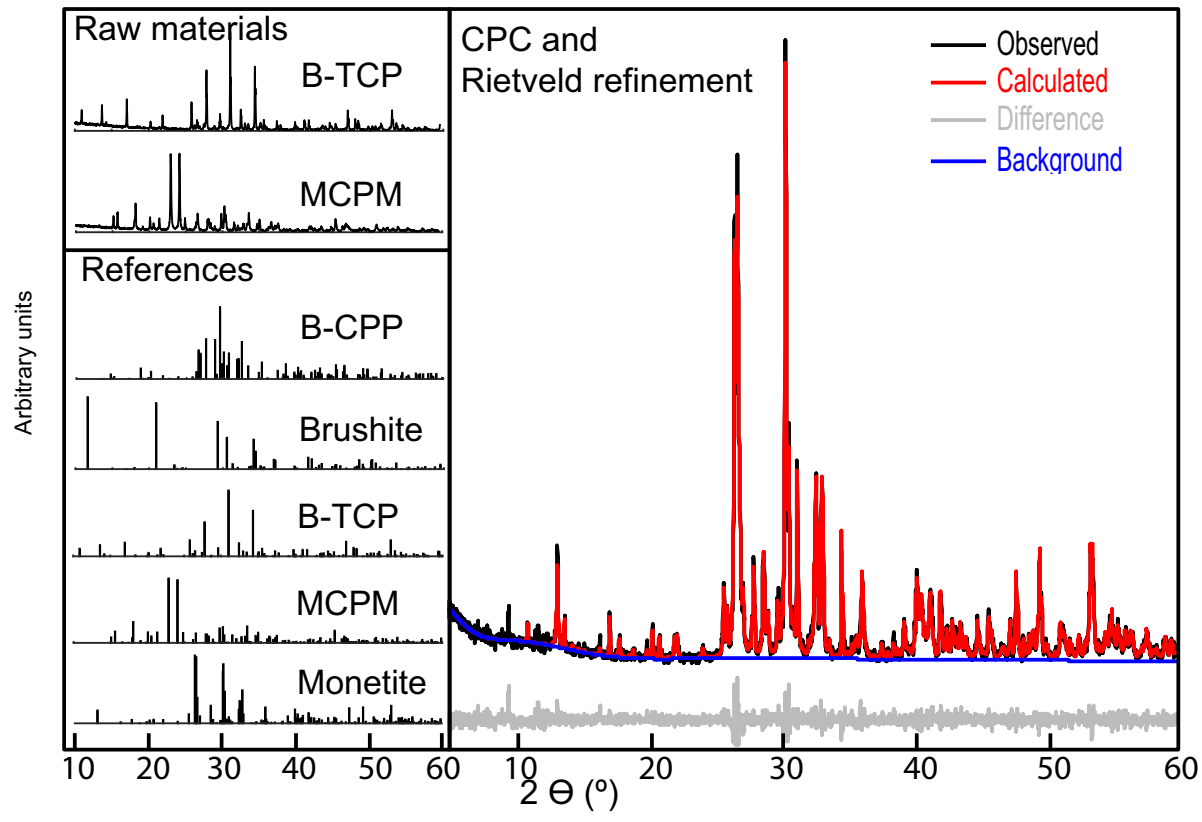

Figure 6. XRD patterns of raw materials and references used for Rietveld refinement together with a representative XRD pattern showing the accuracy of the refinement. The analysis show that the $\beta$-CPP phase exists as an impurity in the $\beta$-TCP raw material and that all brushite has transformed into monetite.

than cage housed rabbits. For details see Hedenqvist et al [29].

\subsection{Animals}

Six rabbits were lost during the study. One was related to the animal model; the heaviest rabbit fractured the ulna of the operated leg two days postoperatively. The other losses were unrelated to the animal model; one rabbit died before the study start (endotoxemia) and one during anesthesia before onset of surgery (cardiac arrest). Complications from arterial blood sampling caused three losses (one from hypovolemic shock and two from brain infarctions). The 14 remaining rabbits had the following distribution: CPC + cage $(n=3)$; $\mathrm{CPC}+$ floor $(n=3) ; \mathrm{AB}+$ cage $(n=4) ; \mathrm{AB}+$ floor $(n=4)$. These rabbits recovered uneventfully from the surgery and remained clinically healthy during the study. Gross pathology revealed no changes.

\subsection{Crystal phase characterization}

A representative XRD pattern of the CPC implant before surgery and the reference samples as well as the accuracy of the Rietveld refinement are shown in figure 6. The phase composition of the CPC was $83 \mathrm{wt} \%$ monetite, $10 \mathrm{wt} \% \beta$-TCP and $7 \mathrm{wt} \% \beta$-CPP. The repeatability of the measurements was calculated and found to be better than $1.2 \mathrm{wt} \%$.

\section{3. $\mu \mathrm{CT}$ analyses}

\subsubsection{Qualitative $\mu C T$ evaluation}

The correlations between observers were good $(r=0.83-1, p<0.001)$. There were no interactions between material and housing on either bridging score or filling of the defect ( $p=0.4$ and 0.36 respectively). The material had no effect on the bridging score (CPC: 3.3 (1-4); AB: 4 (3.7-4), $p=0.06$ ), whereas the $\mathrm{CPC}$ group showed a higher score for filling of the defect $(4.0(3.3-4))$ than $\mathrm{AB}(3.2(1-4))$, $p=0.0495$. In one of the CPC treated defects the implant was fractured and dislocated (figure 7(B)). Otherwise, the CPC implants were generally found in their original shape but with small cracks and bone formation (figure $7(\mathrm{~A})$ ) adjacent to the larger $\mathrm{CPC}$ sections. The outcome for the $\mathrm{AB}$ treated defects ranged from complete union (figure $7(\mathrm{C})$ ) to an almost complete loss of $\mathrm{AB}$ without new bone formation (figure $7(\mathrm{D})$ ).

\subsubsection{Quantitative $\mu C T$ evaluation}

The quantitative $\mu \mathrm{CT}$ analysis showed that material and housing had no main effects in the comparison of the unrestricted and restricted VOIs for defect filling (VOI $20 \mathrm{~mm}: p=0.83$ and 0.18 , respectively; VOI $10 \mathrm{~mm}: p=0.75$ and 0.20 , respectively). The combined volume of bone and graft material was found to be larger in the unrestricted VOIs than the corresponding restricted VOIs (VOI $10 \mathrm{~mm}: p=0.0002$, VOI $20 \mathrm{~mm}: p=0.0019$, figure 8).

There were no interactions with housing conditions, or main effects of material on volume in any of the VOIs ( $10 \mathrm{~mm}$ restricted: $p=0.54$ and 0.61 ; $10 \mathrm{~mm}$ unrestricted: $p=0.34$ and $0.52 ; 20 \mathrm{~mm}$ restricted: $p=0.33$ and $0.50 ; 20 \mathrm{~mm}$ unrestricted: $p=0.5$ and 0.5 ), figure $9(\mathrm{~A})$.

For density no interactions between material and housing were found for any of the VOIs $(10 \mathrm{~mm}$ 


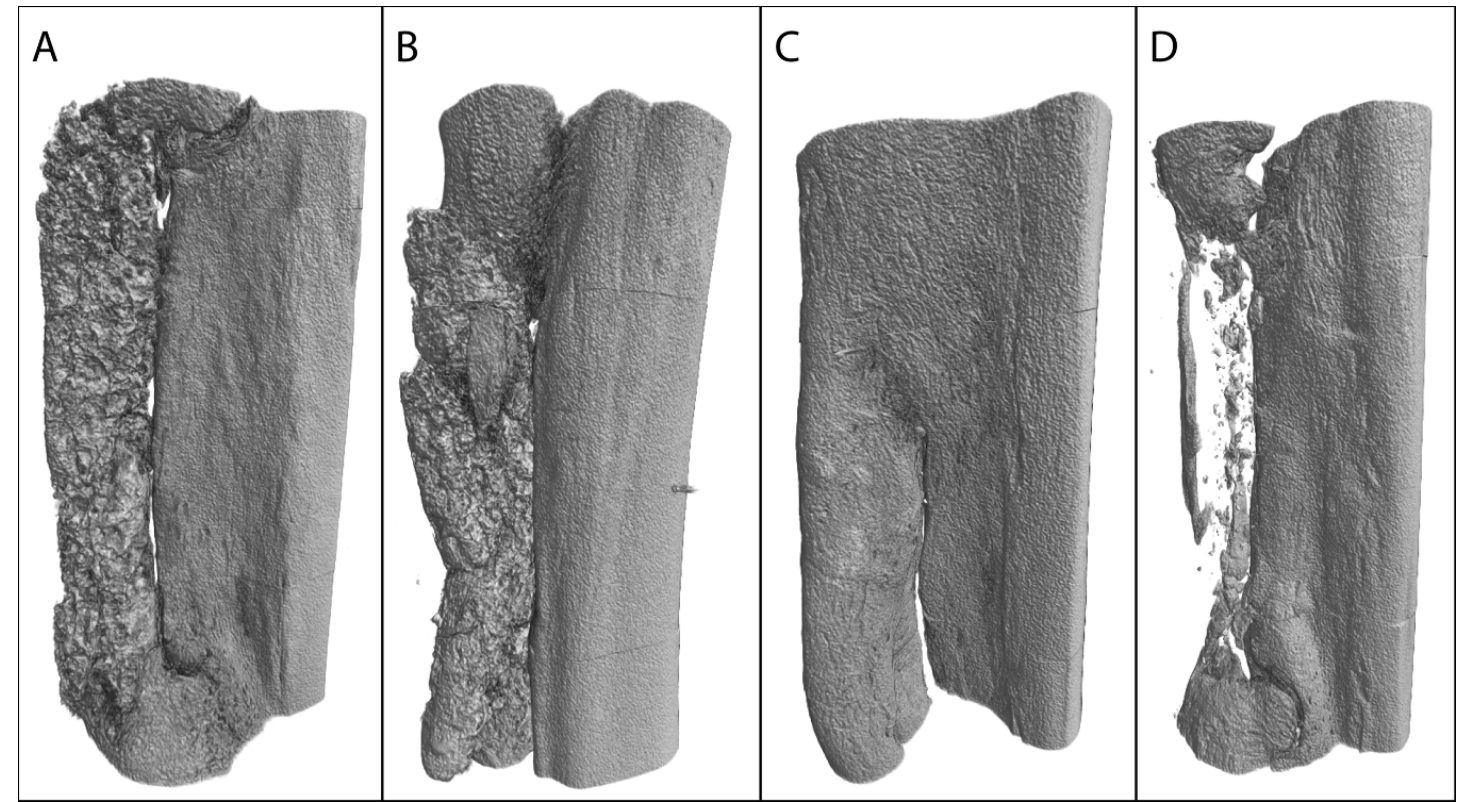

Figure 7. $\mu \mathrm{CT}$ images of the defects 12 weeks after surgery that represent the variation of outcomes in the two groups. (A) Integrated CPC implant without visible fractures. (B) Fractured and partly dislocated CPC Implant. (C ) and (D) Two defects filled with $\mathrm{AB}$ showing the variation of the formed bone amount.

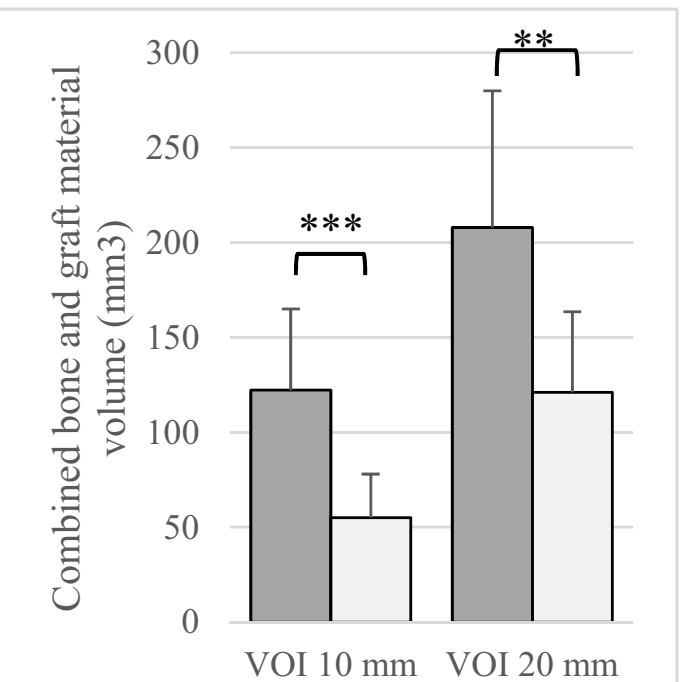

口Unrestricted volume

$\square$ Restricted volume

Figure 8. Quantification of the amount of bone combined with remnants of the graft materials based on $\mu \mathrm{CT}$ analysis (mean, SD, $n=14$ ). The unrestricted volume was larger than the restricted for both volumes of interest (VOI). ${ }^{* *} p<0.05,{ }^{* * *} p<0.001$, extended paired t-test, $n=14$.

restricted: $p=0.46 ; 10 \mathrm{~mm}$ unrestricted: $p=0.72$; $20 \mathrm{~mm}$ restricted: $p=0.30 ; 20 \mathrm{~mm}$ unrestricted: $p=0.85)$. One effect of material was found, the density for the restricted VOIs were higher in the animals treated with $\mathrm{CPC}$ compared to $\mathrm{AB}(p<0.01)$, figure $9(B)$.

\subsection{Histology}

\subsubsection{General observations}

The CPC had an appearance of brown/black/dark purple colour, which was easy to identify, and was often present in large amounts in the defect area (figures 10(A), (B) and (E)). Bone formation were found in direct contact to the material in multiple areas along the CPC implants, including sections along the surface of the cavity (figure 10(E)). Both woven and lamellar bone could be found in contact with the material (figure 10(A)). Smaller detached pieces of material were detected, these were pale brown and embedded in soft tissue and often seen within macrophage-like cells. (figures 10(A) and (B)).

The remnants of $A B$ could not be distinguished from newly formed bone, which meant that the amount of new bone could not be quantitatively evaluated. In a few sections, small acellular bone pieces, probably remnants of $A B$, were surrounded by trabecular or lamellar bone (figure $10(\mathrm{C})$ ). The bone in the $\mathrm{AB}$ treated defects displayed varying cortical and cancellous maturation, ranging from woven bone to complete reorganisation with lamellar bone in cortical and medullary areas. In some of the AB treated defects, fibrocartilage was found, which resulted in transverse areas without bone fusion.

Inflammatory cells were present in multiple areas of the defect and in the periosteal fibrous tissue. The cells were mostly mononuclear and showed macrophage/monocyte characteristics. Sometimes a few multinucleated giant cells (figure 10(D)) were seen either in association with the CPC or in the loose fibrous tissue between and close to bone tissue. The 


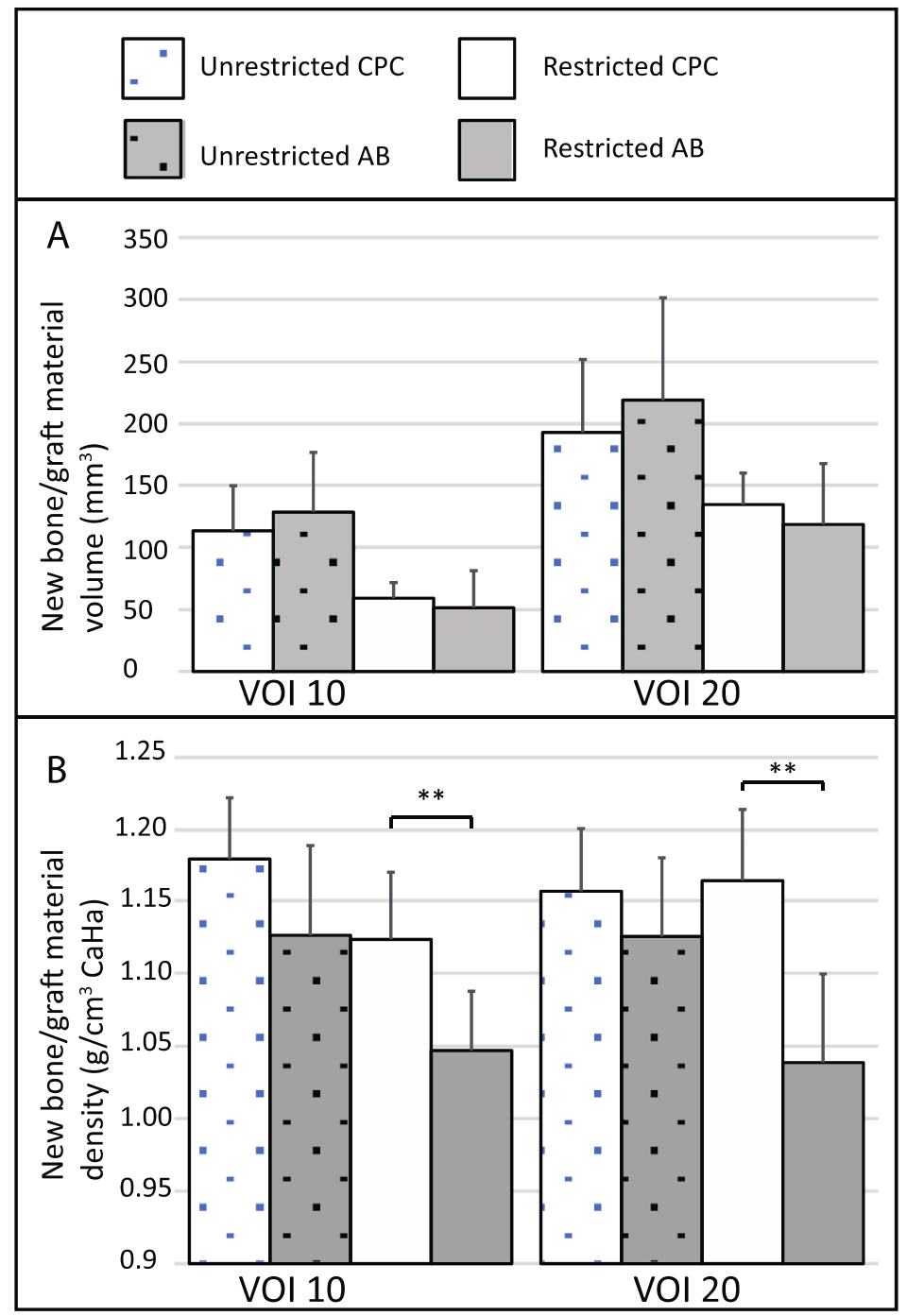

Figure 9. (A) Quantification of the volume of the bone combined with remnants of the graft materials based on $\mu \mathrm{CT}$ analysis (mean, SD). There were no differences between materials $(\mathrm{CPC}=$ calcium phosphate cement implant $(n=6), \mathrm{AB}=$ autologous bone graft $(n=8)$ ), Two-way ANOVA, post-hoc comparison test LSD, VOI = volume of interest. (B) Quantification of the density of the bone combined with remnants of the graft materials based on $\mu C T$ analysis (mean, SD). The density of the unrestricted volumes was higher for CPC than for $\mathrm{AB} .\left({ }^{* *} p<0.01\right.$, two-way ANOVA, post-hoc comparison test LSD). $\mathrm{CPC}=$ calcium phosphate cement implant $(n=6), \mathrm{AB}=$ autologous bone graft $(n=8)$, VOI = volume of interest.

CPC treated defects often displayed regions with a higher cell concentration compared to the $\mathrm{AB}$ treated defects. Fibrous periosteum-like tissue formation, mostly found in the $\mathrm{AB}$ treated defects, often contained mononuclear cells diffusely distributed. The fibrous tissue was sometimes dense and oriented parallel to the peripheral bone surface, probably representing part of the collagen membrane used with $\mathrm{AB}$ treatment.

\subsubsection{Histomorphometry}

For the CPC group separation of new bone formation from graft material was possible, enabling quantification of both CPC $\left(9.4 \pm 3.4 \mathrm{~mm}^{2}\right)$ and new bone $\left(13.3 \pm 3.7 \mathrm{~mm}^{2}\right)$ respectively. The remnants of the $\mathrm{AB}$ graft could however not be distinguished from the new bone $\left(17.2 \pm 5.2 \mathrm{~mm}^{2}\right.$ ), (figure $11(\mathrm{~A})$ ).
There were no interactions between material and housing for the total measured defect area $(p=0.91)$, and no effect of material $(p=0.42)$. Likewise, there were no interactions, or effect of material on the area filled with bone and graft material $(p=0.38$ and 0.09 , respectively). There was an interaction between material and housing for the fraction filled area $(p=0.03)$; the fraction was larger in the CPC than the $\mathrm{AB}$ group only in floor housed rabbits $(p=0.024)$ (figure 11(B)).

\subsubsection{Histology scoring}

There were no interactions between material and housing for any of the parameters. Group AB showed higher scores for cortical integrity and presence of cancellous bone than CPC in both longitudinal and transversal sections, as well as for defect filling composition in longitudinal sections and for bony fusion 


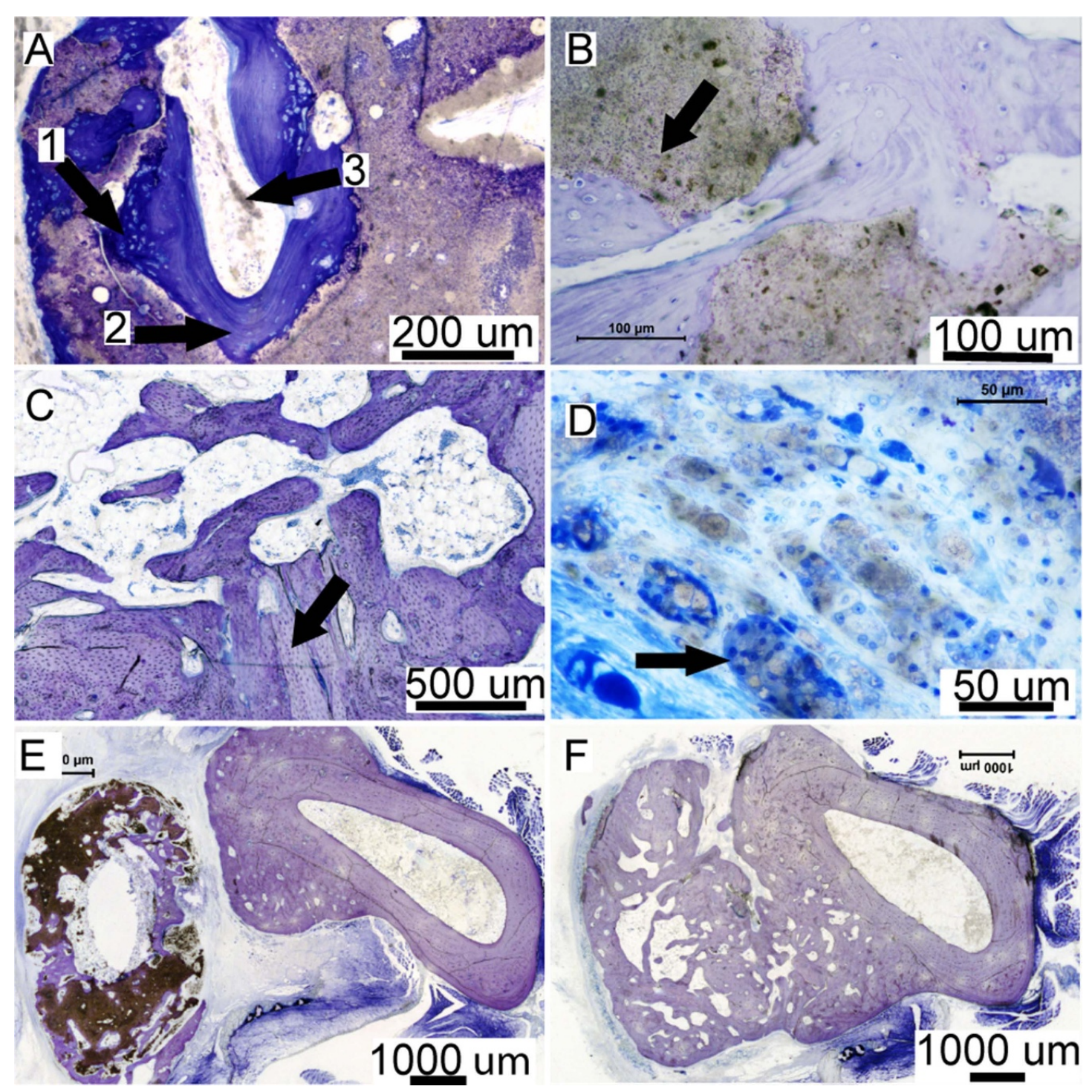

Figure 10. Histology images showing (A) a CPC section with arrows pointing to (1) woven bone, (2) lamellar bone formation and (3) detached pieces of the graft material. (B) The second picture is a $200 \times$ magnification of a CPC area showing new bone formation in contact to the material, arrow pointing at the CPC material. (C) The third picture is showing an AB section with lighter purple coloured pieces that are integrated in a darker coloured bone and might be the remnant of the $\mathrm{AB}$ graft. (D) This image presents the inflammatory cells that are present in CPC sections, the arrow points to a multinucleated cell as seen containing/in contact with small pieces of graft material. The last two pictures show transvers sections of the two defects (E) a $\mathrm{CPC}$ section from the middle of the defect. Bone is seen in contact with the material in several places, there is a soft tissue space between ulna and radius, and $(\mathrm{F})$ is showing an $\mathrm{AB}$ section, the ulnar bone and the bone formation in contact to it.

with the ulna at the defect in transversal sections, figure 12 .

In the longitudinal sections, both $\mathrm{CPC}$ and $\mathrm{AB}$ showed integration with new bone in the proximal and distal defect ends with no differences between materials $(p=0.4)$. Peripheral cortical integrity was often absent in the CPC sections, with only some of the transverse sections showing initiation of lamellar bone formation. The $\mathrm{AB}$ sections on the other hand showed a variety of cortical maturation. When evaluating the cancellous maturation, the CPC sections presented small amounts of woven and lamellar bone in contact with the graft material. The $A B$ sections present large areas of bone with complete reorganization of trabecular bone replacing the defect but as mentioned before it was not possible to identify the remnants of the $\mathrm{AB}$ material. $\mathrm{CPC}$ defects were filled with large amounts of graft material, varying amounts of bone, and loose fibrous tissue. The $\mathrm{AB}$ sections displayed a range of filling with bone, including bone marrow and loose fibrous tissue to near total bony reconstruction. Ulnar periosteal reactions could be observed in both the $\mathrm{CPC}$ and $\mathrm{AB}$ sections. The CPC treated defects displayed this to a lesser extent and with less fusion between the radius and ulna, especially in the middle parts of the defects (figure $10(\mathrm{E})$ ). AB sections on the other hand showed an extensive area of reactive periosteal proliferation 


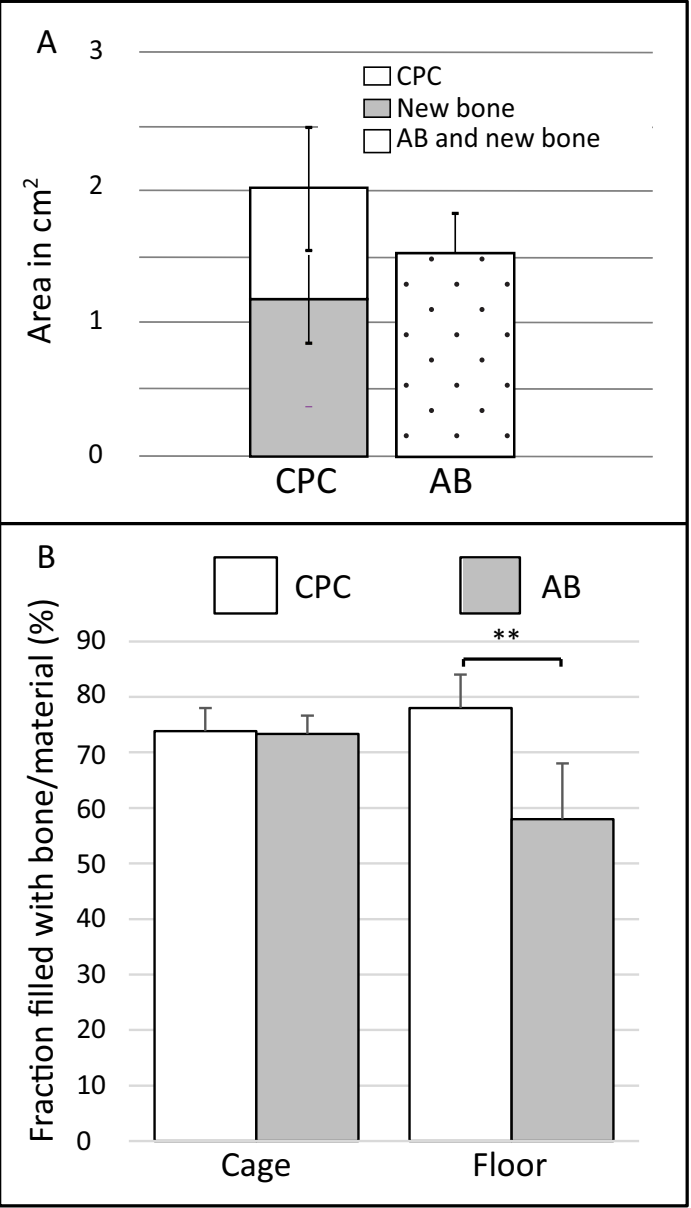

Figure 11. (A) Graph presenting the average filled area $\left(\mathrm{mm}^{2}\right)$ of the CPC and AB defects. The CPC column displays both the CPC (white) and solely new bone fraction (red) (41\% and 59\%, respectively). The AB column displays the graft and bone area (blue). No significant difference could be detected between the two materials when graft and bone area was measured $(p=0.09)$. (B)

Histomorphometry data: percentage of total area filled with new bone/graft material in rabbits housed in cages of $0.43 \mathrm{~m}^{2}$ or floor pens of $3 \mathrm{~m}^{2}$ (mean, SD) There was an interaction between housing factors $(p=0.03)$. The area was larger in the CPC group only in floor-housed rabbits. ( ${ }^{* *} p<0.05$, two-way-ANOVA, post-hoc comparison test LSD). CPC = calcium phosphate cement implant, $\mathrm{AB}=$ autologous bone graft, $\mathrm{CPC}+$ cage $(n=3)$, $\mathrm{CPC}+$ floor $(n=3), \mathrm{AB}+$ cage $(n=4), \mathrm{AB}+$ floor $(n=4)$.

with fusion between ulna and radius (figure 10(F)). No significant difference was seen between the CPC and $\mathrm{AB}$ materials in regard to bony fusion of ulna and radius in areas adjacent to defects (longitudinal sections $p=0.6$ ). Inflammatory cells were present in all the $\mathrm{CPC}$ and most of the $\mathrm{AB}$ sections, and there was no difference in the presence of inflammation between the two materials (longitudinal sections and transversal sections $p=0.4$ ).

The transversal sections showed similar morphology as the longitudinal sections, however, new bone formation adjacent to the defect ends, defect filling composition and bony fusion between ulna and radius adjacent to the defect could not be evaluated in these sections.

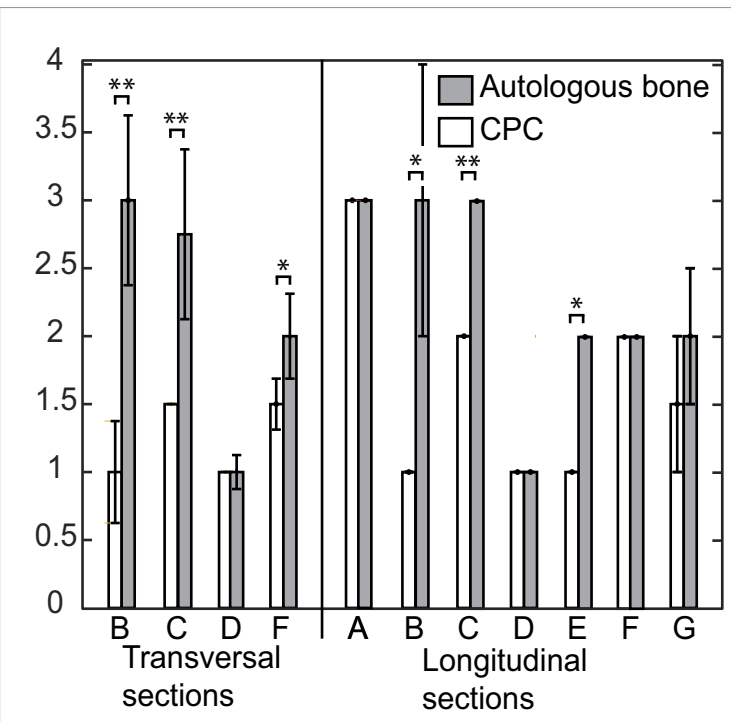

Figure 12. Scores (mean, SD) of transversal and longitudinal histology sections. (A) New bone formation associated with defect ends; (B) cortical integrity; (C) cancellous bone; (D) inflammation; (E) filling of the defect; (F) bony fusion with ulna at the defect and $(\mathrm{G})$ bony fusion between ulna and radius adjacent to defect.

(Mann-Whitney test, ${ }^{*} p<0.05,{ }^{* *} p<0.01$ ).

\section{Discussion}

The rabbit is considered a suitable species for the study of segmental defects and for studying grafts with structural properties [45]. The radius critical defect model is relatively straightforward and requires no additional fixation, but its suitability has been controversial in recent years. Bodde et al studied 15 and $20 \mathrm{~mm}$ radius defects in 4 months old rabbits and found that the defects were not critical [38]. On the other hand, Zhao et al found that radius defects remained critical after 12 weeks of healing provided that: the periosteum was removed; the defects were larger than $12 \mathrm{~mm}$ and that the animals were mature in age [25]. Further, Kasten and Niemeyer showed that there was no bone union after 16 weeks if $5 \mathrm{~mm}$ of the periosteum was removed proximal and distal of a $15 \mathrm{~mm}$ defect in mature animals $[46,47]$. In the present study, the size of the defect was $20 \mathrm{~mm}$ and adult rabbits were used. No untreated controls were included and the periosteum outside the defect area was left intact. Taking the aforementioned studies into consideration, the defects in the present study should indeed be of a critical size. The osseous proliferation of the ulnar bone and the fusion with the radius complicated the evaluation of osseoinductive and osseoconductive properties in the present study. Future studies may benefit from a defect model in a singular long bone, e.g. rabbit femur, with internal or external fixation $[48,49]$. For the sake of reducing the number of animals used in experimental research, the effects of housing conditions were evaluated in the same study. Floor-housed rabbits showed an increased skeletal muscle enzyme activity, which 
promoted a larger defect filling volume and a higher score of bony fusion between radius and ulna, independent of the material [29]. Simultaneously, larger housing conditions resulted in a more active physical behavior that potentially could have increased the risk of injury.

The soft collagen membrane that was used in the present study to keep the $\mathrm{AB}$ in place was expected to be resorbed after 12 weeks [50]. Considering that $\mathrm{AB}$ was found outside were the membrane was originally placed it was evident that the collagen membrane did not fully stop the migration of the AB. The use of a non-resorbable membrane may have avoided this $[51,52]$.

The indirect 3D printing method, developed to produce the implants, combined the design freedom of $3 \mathrm{D}$ printing, without the need to optimize the material for a specific printer. This allows for manufacturing of complex implants using most cement formulations, including already developed bioceramic cements.

Previous studies on monetite based bioceramics have proven that they have important qualities such as osseointegration, osteoconduction and osteoinduction [8]. However, the resorption rate of the implant material is also a crucial property; if the rate of resorption is faster than new bone formation, an ingrowth of soft tissue can be expected. If the rate is too slow, new bone will be blocked from filling the defect. Chu et al [53] showed that a controlled internal macro architecture can be used to fill a large bone void and still achieve bone formation within the implant. The central canal through the implant could allow for the use of a slower resorbing material that is able to uphold the defect and stop in-growth of soft tissue, as well as creating space for new bone to form within the canal, as well as allowing cells and nutrients reaching further into the implant. Histology showed that a part of the bone formation occurred on the surface of the cavity, ossifying the implant from within.

From the radiographic and histological analyses, it was evident that new bone formation had occurred along the entire CPC implant, indicating bone conducting properties. The $\mathrm{AB}$ treated defects gave a useful comparison for the efficacy of the treatment and showed, in some cases, that it is possible to obtain good long bone regeneration with particulate $A B$ with cancellous maturity after 12 weeks. However, $A B$ was unpredictable, presenting a wide variety of bone formation ranging from large bone voids to totally restored radii.

Based upon subjective histologic evaluation CPC group showed less cortical integrity, amount of cancellous bone and defect filling composition compared to $\mathrm{AB}$ group. This was expected and in line with a previous comparison between calcium phosphate based materials and $\mathrm{AB}$ [54]. A large part of the new bone formation occurred as osseous periosteal proliferation of the ulnar bone, especially in the $\mathrm{AB}$ group.
Both Bodde et al and Zhao et al observed this occurrence of ulnar osseous hypertrophy when they analysed different critical size defects of radius in rabbits $[25,38]$. The use of a non-resorbable membrane could potentially have isolated the ulna from effecting the bone formation in the radius defect.

Remnants of $\mathrm{AB}$ chips were difficult or impossible to distinguish from the newly formed bone in the histologic sections as perfusion with differential staining for new bone formation was not used. With calcein green injections this problem could have been avoided as suggested by Zhao et al [25]. A morphometric evaluation was performed to further quantify the proportion of filling and the amount of bone in the radius defects. This showed that the degree of filling with bone and graft material combined was similar in both groups. Interestingly, 59\% of the measured mineral area in the CPC defects consisted of new bone, although the ulnar bone thickening was a substantial portion of this area. In the $\mathrm{AB}$ sections, the influence of ulnar bone proliferation was also evident.

The inflammatory response was similar in both the $\mathrm{CPC}$ and $\mathrm{AB}$ treated defects, however in the CPC sections the inflammatory cells, including multinucleated cells were seen in contact with the graft material, especially with the detached particles. This response to similar materials has been described before as a part of osteoclastic resorption of the material $[55,56]$. The CPC treated defects displayed less bone proliferation and fusion with the ulna at the middle part of the defect compared to the $\mathrm{AB}$ treated defects. In the CPC treated defects, new bone formation was mostly seen close to the bony ends of the radius, inside pores and the inner cavity of the CPC implant, away from the periosteum and the ulnar bone. These findings indicate that the bone formation followed the scaffold rather than the adjacent ulnar bone.

The newly formed bone inside the CPC scaffold possibly provided mechanical stability to the otherwise brittle implant. Even though the walls of the implants were quite thin, only one fractured and a dislocation of the implant could be observed. The implants did however have plenty of internal cracks that likely were caused by trauma after implant insertion in combination with loading and material degradation.

The area of combined bone and graft material was quantified in four different regions, with two different strategies, to give an understanding of where the bone and graft material could be found. The results showed no difference in volume between $\mathrm{CPC}$ and $\mathrm{AB}$ treated defects using $\mu \mathrm{CT}$, but that large parts of the bone and graft material were located outside its intended place. The radiographic scoring of the reconstructions concluded that the $\mathrm{CPC}$ was similar to $\mathrm{AB}$ regarding bridging of the defect, and slightly better at filling the defect. The use of $\mu \mathrm{CT}$ to quantify bone formation is challenging when working with materials that have 
similar radiopacity to bone, and in the current study, the difference in radiopacity between graft material and bone was too small to differentiate the two. A combination of several different methods including histology and 3D reconstructions helped in the evaluation of the CPC implant since no single technique gave enough information to draw reliable conclusions of the efficacy of the treatment.

\section{Conclusion}

In conclusion, the in vivo evaluation showed that the developed CPC implant integrated with the new bone showing osteoconductive properties. Integration between the implant and new bone may have contributed to the implant remaining stable throughout the study without any external fixation. Before this type of CPC implants could be used in clinical practice, longer duration studies are needed to evaluate continued bone formation across the defect as well as the fate of the CPC material.

\section{Acknowledgment}

The Swedish Research Council (VR Grant 2013-5419) is recognized for providing financial support for this project. The authors declare no potential conflicts of interest with respect to the publication of this article.

\section{ORCID iD} Öhman-Mägi Caroline ํㅏ https://orcid.org/0000-
0003-2709-9541

\section{References}

[1] Wennergren D, Bergdahl C, Ekelund J, Juto H, Sundfeldt M and Moller M 2018 Epidemiology and incidence of tibia fractures in the Swedish Fracture Register Injury 49 2068-74

[2] Ekegren C L, Gabbe B J, Edwards E R, de Steiger R and Page R 2016 Incidence, costs and outcomes of non-union and mal-union following long bone fracture Inj. Prev. 22 A283

[3] Pape H C, Evans A and Kobbe P 2010 Autologous bone graft: properties and techniques J. Orthop. Trauma 24 S36-40

[4] Younger E M and Chapman M W 1989 Morbidity at bone graft donor sites J. Orthop. Trauma 3 192-5

[5] Nkenke E and Neukam F W 2014 Autogenous bone harvesting and grafting in advanced jaw resorption: morbidity, resorption and implant survival Eur. J. Oral Implantol. 7 S203-17

[6] Frohberg U and Mazock J B 2005 A review of morbidity associated with bone harvest from the proximal tibial metaphysis Mund Kiefer Gesichtschir 9 63-5

[7] Best SM, Porter A E, Thian E S, Huang J 2008 Bioceramics: past, present and for the future J. Eur. Ceram. Soc. 28 1319-27

[8] Habraken W, Habibovic P, Epple M and Bohner M 2016 Calcium phosphates in biomedical applications: materials for the future? Mater. Today 19 69-87

[9] Barba A et al 2018 Osteogenesis by foamed and 3D-printed nanostructured calcium phosphate scaffolds: effect of pore architecture Acta Biomater. 79 135-47
[10] Seeherman H, Li R and Wozney J 2003 A review of preclinical program development for evaluating injectable carriers for osteogenic factors J. Bone Joint Surg. Am. 85-A 96-108

[11] Engstrand T, Kihlstrom L, Lundgren K, Trobos M, Engqvist $\mathrm{H}$ and Thomsen P 2015 Bioceramic implant induces bone healing of cranial defects Plast. Reconstr. Surg. Glob. Open 3 e491

[12] Engstrand T, Kihlstrom L, Neovius E, Skogh A C, Lundgren T K, Jacobsson H, Bohlin J, Aberg J and Engqvist H 2014 Development of a bioactive implant for repair and potential healing of cranial defects J. Neurosurg. 120 273-7

[13] Trbakovic A, Hedenqvist P, Mellgren T, Ley C, Hilborn J, Ossipov D, Ekman S, Johansson C B, Jensen-Waern M and Thor A 2017 A new synthetic granular calcium phosphate compound induces new bone in a sinus lift rabbit model J. Dent. 70 31-9

[14] Burenstam Linder L K, Birgersson U, Lundgren K, Illies C and Engstrand T 2018 Patient-specific titanium reinforced calcium phosphate implant for the repair and healing of complex cranial defects World Neurosurg. 122 e399-e407

[15] Omar O et al 2020 In situ bone regeneration of large cranial defects using synthetic ceramic implants with a tailored composition and design Proc. Natl Acad. Sci. USA 117 26660-71

[16] Ajaxon I, Acciaioli A, Lionello G, Ginebra M P, Ohman-Magi C, Baleani M and Persson C 2017 Elastic properties and strain-to-crack-initiation of calcium phosphate bone cements: revelations of a high-resolution measurement technique J. Mech. Behav. Biomed. Mater. 74 428-37

[17] Jariwala S H, Lewis G S, Bushman Z J, Adair J H and Donahue H J 2015 3D printing of personalized artificial bone scaffolds 3D Print Addit. Manuf. 2 56-64

[18] Vidal L, Kampleitner C, Brennan M A, Hoornaert A and Layrolle P 2020 Reconstruction of large skeletal defects: current clinical therapeutic strategies and future directions using 3D printing Front. Bioeng. Biotechnol. 861

[19] Vidal L, Kampleitner C, Krissian S, Brennan M A, Hoffmann O, Raymond Y, Maazouz Y, Ginebra M P, Rosset P and Layrolle P 2020 Regeneration of segmental defects in metatarsus of sheep with vascularized and customized 3D-printed calcium phosphate scaffolds Sci Rep. 107068

[20] Vidal L, Brennan M Á, Krissian S, De Lima J, Hoornaert A, Rosset P, Fellah B H and Layrolle P 2020 In situ production of pre-vascularized synthetic bone grafts for regenerating critical-sized defects in rabbits Acta Biomater. 114 384-94

[21] Bose S, Vahabzadeh S and Bandyopadhyay A 2013 Bone tissue engineering using 3D printing Mater. Today 16 496-504

[22] Maazouz Y, Montufar E B, Guillem-Marti J, Fleps I, Ohman C, Persson C and Ginebra M P 2014 Robocasting of biomimetic hydroxyapatite scaffolds using self-setting inks J. Mater. Chem. B 2 5378-86

[23] Simon C G Jr, Yaszemski M J, Ratcliffe A, Tomlins P, Luginbuehl R and Tesk J A 2014 ASTM international workshop on standards and measurements for tissue engineering scaffolds J. Biomed. Mater. Res. B 103 949-59

[24] Muschler G F, Raut V P, Patterson T E, Wenke J C and Hollinger J O 2010 The design and use of animal models for translational research in bone tissue engineering and regenerative medicine Tissue Eng. B 16 123-45

[25] Zhao M D, Huang J S, Zhang X C, Gui K K, Xiong M, Yin W P, Yuan F L and Cai G P 2016 Construction of radial defect models in rabbits to determine the critical size defects PLoS One 11 e0146301

[26] Hollinger J O and Kleinschmidt J C 1990 The critical size defect as an experimental model to test bone repair materials J. Craniofac. Surg. 1 60-8

[27] Swedish Department of Agriculture Ordinance 2017 Statens jordbruksverks föreskrifter och allmänna råd om försöksdjur Saknr L 150 SJVFS 40

[28] Mähler M, Berard M, Feinstein R, Gallagher A, Illgen-Wilcke B, Pritchett-Corning K and Raspa M 2014 FELASA recommendations for the health monitoring of 
mouse, rat, hamster, guinea pig and rabbit colonies in breeding and experimental units Lab. Animals 48 178-92

[29] Hedenqvist P, Trbakovic A, Mellgren T, Ohman-Magi C, Hammarstrom Johansson P, Manell E, Ekman S, Ley C, Jensen-Waern M and Thor A 2020 The effect of housing environment on bone healing in a critical radius defect in New Zealand White rabbits PLoS One 15 e 0233530

[30] Taut T, Kleeberg R and Bergmann J 1998 The new Seifert Rietveld program BGMN and its application to quantitative phase analysis Mater. Struct. 5 57-66

[31] Bergmann J, Friedel P and Kleeberg R 1998 BGMN-a new fundamental parameters based Rietveld program for laboratory X-ray sources, its use in quantitative analysis and structure investigations Int. Union Crystallogr. (Newslett.) 20 5-8

[32] Doebelin N and Kleeberg R 2015 Profex: a graphical user interface for the Rietveld refinement program BGMN $J$. Appl. Crystallogr. 48 1573-80

[33] Curry N and Jones D 1971 Cristal structure of burette, calcium hydrogen orthophosphate dihydrate: aneutrondiffraction investigation J. Chem. Soc. A 3725-9

[34] Dickens B, Schroeder L W and Brown W E 1974 Crystallographic studies of the role of $\mathrm{Mg}$ as a stabilizing impurity in $\beta-\mathrm{Ca}_{3}\left(\mathrm{PO}_{4}\right)_{2}$. The crystal structure of pure p-Ca ${ }_{3},\left(\mathrm{PO}_{4}\right)_{2}$ J. Solid State Chem. $10232-48$

[35] Dickens B, Bowen J and Brown W 1971 A refinement of the crystal structure of $\mathrm{CaHPO}_{4}$ (synthetic monetite) Acta Crystallogr. C B28 797-806

[36] E177-14 2014 Standard practice for use of the terms precision and bias in ASTM test methods 1

[37] Freijs E 2016 Comparison of plasma levels and analgesic effect between oral transmucosal and subcutaneous administration of buprenorphine in rabbits (Uppsala: Dept. of Clinical Sciences Swedish University of Agricultural Sciences) 46

[38] Bodde E W, Spauwen P H, Mikos A G and Jansen J A 2008 Closing capacity of segmental radius defects in rabbits J. Biomed. Mater. Res. A 85 206-17

[39] Donath K and Breuner G 1982 A method for the study of undecalcified bones and teeth with attached soft tissues. the Säge-Schliff (sawing and grinding) technique J. Oral Pathol. $11318-26$

[40] Donath K 1985 The diagnostic value of the new method for the study of undecalcified bones and teeth with attached soft tissue (Säge-Schliff (sawing and grinding) technique) Pathol. Res. Pract. 179 631-3

[41] Johansson C, Roeser K, Jimbo R, Hammarström Johansson P, Larsson L and Östberg A K 2017 Histological analysis Comprehensive Biomaterials II ed D W Grainger, P Ducheyne, K E Healy, D W Hutmacher and C J Kirkpatrick (Amsterdam: Elsevier) pp 335-63

[42] Johansson C B and Morberg P 1995 Importance of ground section thickness for reliable histomorphometrical results Biomaterials 16 91-5
[43] Bate S and Clark R 2014 The Design and Statistical Analysis of Animal Experiments (Cambridge: Cambridge University Press)

[44] Snedecor G W and Cochran W G 1989 Statistical Methods (Iowa: Iowa State University)

[45] Bigham-Sadegh A and Oryan A 2015 Selection of animal models for pre-clinical strategies in evaluating the fracture healing, bone graft substitutes and bone tissue regeneration and engineering Connect. Tissue Res. 56 175-94

[46] Kasten P, Vogel J, Geiger F, Niemeyer P, Luginbuhl R and Szalay K 2008 The effect of platelet-rich plasma on healing in critical-size long-bone defects Biomaterials 29 3983-92

[47] Niemeyer P, Szalay K, Luginbuhl R, Sudkamp N P and Kasten P 2010 Transplantation of human mesenchymal stem cells in a non-autogenous setting for bone regeneration in a rabbit critical-size defect model Acta Biomater. 6 900-8

[48] Fujibayashi S, Kim H M, Neo M, Uchida M, Kokubo T and Nakamura T 2003 Repair of segmental long bone defect in rabbit femur using bioactive titanium cylindrical mesh cage Biomaterials 24 3445-51

[49] Kojimoto H, Yasui N, Goto T, Matsuda S and Shimomura Y 1988 Bone lengthening in rabbits by callus distraction. The role of periosteum and endosteum J. Bone Joint Surg. Br. 70 543-9

[50] von Arx T, Broggini N, Jensen S S, Bornstein M M, Schenk R K and Buser D 2005 Membrane durability and tissue response of different bioresorbable barrier membranes: a histologic study in the rabbit calvarium Int. J. Oral Maxillofac. Implants 20 843-53

[51] Dahlin C, Sennerby L, Lekholm U, Linde A and Nyman S 1989 Generation of new bone around titanium implants using a membrane technique: an experimental study in rabbits Int. J. Oral Maxillofac. Implants 4 19-25

[52] Caballe-Serrano J, Munar-Frau A, Ortiz-Puigpelat O, Soto-Penaloza D, Penarrocha M and Hernandez-Alfaro F 2018 On the search of the ideal barrier membrane for guided bone regeneration J. Clin. Exp. Dent. 10 e477-83

[53] Chu T M, Orton D G, Hollister S J, Feinberg S E and Halloran J W 2002 Mechanical and in vivo performance of hydroxyapatite implants with controlled architectures Biomaterials 23 1283-93

[54] Bloemers F W, Blokhuis T J, Patka P, Bakker F C, Wippermann B W and Haarman H J 2003 Autologous bone versus calcium-phosphate ceramics in treatment of experimental bone defects J. Biomed. Mater. Res. B 66 526-31

[55] Basle M F, Chappard D, Grizon F, Filmon R, Delecrin J, Daculsi G and Rebel A 1993 Osteoclastic resorption of Ca-P biomaterials implanted in rabbit bone Calcif. Tissue Int. 53 348-56

[56] Montazerolghaem M, Karlsson Ott M, Engqvist H, Melhus H and Rasmusson A J 2015 Resorption of monetite calcium phosphate cement by mouse bone marrow derived osteoclasts Mater. Sci. Eng. C 52 212-8 